\title{
Empowered women, social networks and the contribution of qualitative research: broadening our understanding of underlying causes for food and nutrition insecurity
}

\author{
S Lemke ${ }^{1, *}, \mathrm{HH}$ Vorster ${ }^{2}$, NS Jansen van Rensburg ${ }^{3}$ and J Ziche ${ }^{4}$ \\ ${ }^{1}$ Center for International Development and Environmental Research, Justus-Liebig University Giessen, \\ Otto-Behaghel-Strasse 10, D-35394 Giessen, Germany: ${ }^{2}$ Faculty of Health Sciences, Potchefstroom University, \\ South Africa: ${ }^{3}$ School of Social Studies, Potchefstroom University, South Africa: ${ }^{4}$ Department of Rural Sociology, \\ Center of Life Sciences, Technical University of Munich-Weihenstephan, Germany
}

Submitted 10 February 2003: Accepted 20 May 2003

\begin{abstract}
Objective: To investigate underlying causes for food and nutrition insecurity in black South African households and to gain understanding of the factors contributing to better nutrition security, with emphasis on household organisation, gender and intrahousehold dynamics and social networks.

Design, setting and subjects: Within a larger cross-sectional survey that investigated the impact of urbanisation on the health of black South Africans, 166 people, mostly women, were interviewed on household food security. Methods used were structured face-to-face interviews, in-depth interviews, observation, interviews with key informants and a sociodemographic questionnaire. Information was collected from 1998 to 2000 in 15 rural and urban areas of the North West Province, South Africa. Results: Three-quarters of households in this sample are chronically food-insecure. Families are disrupted, due to migrant work, poverty and increasing societal violence, and half of households are female-headed. Certain categories of female-headed households and households based on partnership relationships, despite more limited resources, achieve a better or an equal economic status and better nutrition security than those households led by men, with the latter often being considered an economic liability. The reliance on and fostering of social ties and networks appear to be of central significance.

Conclusion: Gender and intra-household relations, as well as social networks and income from informal sector activities, are often not uncovered by conventional statistical methods. Qualitative research can reveal the unexpected and furthermore empowers people, as their voices are heard.
\end{abstract}

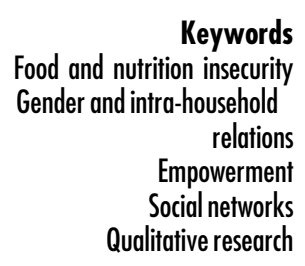

Poverty and food insecurity are among the most pressing social issues in South Africa and the sub-continent at the beginning of the 21st century. According to figures released in 2000, about $44 \%$ of the South African population are food-insecure ${ }^{1}$. While widely held public opinion still associates hunger mainly with emergencies, conflict and calamities, greater awareness needs to be created of the chronic dimensions of food insecurity, its multiple negative effects and its links with poverty ${ }^{2}$.

Apart from external factors that cannot be influenced as easily, whether a household is able to achieve food security depends to a great extent on how available resources are used and distributed in the household. The necessity of revealing the marked differentiation in resource access and decision-making in the household sphere and also between socially connected households has been indicated as being of utmost importance ${ }^{3}$. Although female-headed households, in general, are worse off with regard to resource endowment and access to income, land and property, they still seem to take better care of themselves and their children with the little they have $^{4,5}$. The important role that gender relations play in the general well-being of members of black South African households, especially for women and children, has been described in a number of anthropological studies ${ }^{6-9}$, indicating that male dominance is still very prevalent in the majority of conjugal relationships and that there are conflicts within households, mainly about income and other resources. In a number of these studies, not only the disruptive effects of powerlessness are described, but also the innovative social mechanisms of survival, of which social and individual actions for improved food and 
nutrition security are essential elements. The specific place of food security as an element of daily survival within the different spheres, however, has still to be studied.

The present paper focuses on:

- characteristics of the different food security categories;

- the association between power relations and per capita income;

- the influence of power relations on the daily experiences of people (worries about food and hunger);

- the influence of power relations on the state of food security; and

- the contribution of qualitative methods to this area of research.

\section{Methodology}

\section{Design and setting of the study}

Research was carried out from 1998 to 2000 in 15 randomly selected rural and urban areas in the North West Province, South Africa ${ }^{10}$, within a larger cross-sectional survey that assessed the impact of urbanisation and the resultant demographic transition on determinants and outcomes of physical and mental health of black South Africans in the North West Province ${ }^{11}$.

For this sub-study, 166 people, mostly women (17.2\% of the larger survey population) were interviewed, following a qualitative approach and using structured face-to-face interviews with open-ended questions, follow-up interviews, life histories and non-participant observations. Furthermore, several key informants were interviewed, among them field assistants who lived in the areas that were visited. Quantitative data on socio-economic factors as well as data on health status were also used for evaluation. Case studies were gained during a number of subsequent visits to participants who had been interviewed on household food security, purposefully selecting them ${ }^{12}$ for the in-depth interviews.

\section{Data analysis}

Answers to the open-ended questions were grouped according to evolving themes, to establish possible analytical concepts and categories. The evolving categories were coded and entered into the Statistical Package for the Social Sciences database (SPSS, Inc., Chicago, IL). This enabled the findings to be quantified and the different issues and concepts to be correlated with one another. Owing to the nature of the data obtained, simple descriptive statistics are used, mainly frequencies, cross-correlations and means. Case studies originating from life histories and in-depth interviews are presented, to describe and illustrate the concepts developed in the study and the meaning of the material gathered.

Internal and external validity were provided through a mix of research operations. For a detailed description of the methodology used the reader is referred to the original study ${ }^{10}$ and other works ${ }^{13-15}$.

\section{Results}

\section{Changing bousebold structures and 'singlebood for security'}

In this research, the structure and organisation of households were investigated in detail and several household categories were established ${ }^{10}$. Only $21 \%$ of households consisted of a nuclear family, while $74 \%$ of households consisted of an extended family comprising kin other than parents or children. Six per cent of households consisted of couples or single individuals. The small number of nucleartype households has also been found in several anthropological studies 6,9 . The South African history of repression, relocation and dispossession resulted in a situation of fluidity, residential instability and disorganisation of households. Nowadays, there are several other factors that are compounding the disruption of families and the maintenance of the migrant labour system, among them high or endemic unemployment, poverty and increasing societal violence.

More than half of the women in this sample lived in household forms other than in a conjugal relationship, and half of households were female-headed. Findings on marital status confirmed that almost all of these women were single, with the majority of them being in the age category of 35 years and above. The figures obtained here correspond with other investigations in South Africa ${ }^{16,17}$. Staying single is a result of social forces, such as migration, but also a result of choice by women and therefore a means of self-empowerment. Jones? uses the term 'singlebood for security', which implies that women often choose to be single rather than to live with a partner whom they regard as an economic liability. Several authors in South Africa had already noted this trend in the $1960 \mathrm{~s}^{18}$. Men, on the other hand, are often not able to marry due to economic constraints that are often the result of unemployment.

\section{Characteristics of the different food security categories}

Food insecurity is not always visible and entails far more than an obvious state of undernutrition. While food security is defined as having physical and economic access to sufficient, safe and nutritious food to meet dietary needs and food preferences for an active and healthy life at all times ${ }^{19}$, its principal meaning refers to the risk of people being hungry. To determine the state of food security, a set of indicators was used ${ }^{10}$ and households were then classified into four categories: 'very insecure', 'insecure', 'relatively secure' and 'secure'. Almost three-quarters (74\%) of households in this sample were insecure or very insecure. Members of these households either regularly experience food shortage and hunger or they 
do not feel secure that they will have enough food. There is also no diversity of food to ensure adequate nutrition. Food-insecure households exist on limited or unpredictable incomes and often on pensions as the main income source. Table 1 shows selected characteristics of the different categories of food security.

\section{Association between power relations and per capita income}

The issues of 'head of household' and 'power relations' were investigated in depth, to get an indication about the underlying dynamics and decision-making in the household sphere ${ }^{20}$. For the purpose of this research, 'head of household' was defined as the person who makes major decisions regarding resources and directly influences other decisions taken in the house. Table 2 compares per capita income according to head of household and power relations.

The comparison revealed that income in the households led by men was about three times that in households led by women and also considerably higher than in households characterised by a partnership relationship. This finding is congruent with national data ${ }^{21}$ and confirms the frequent assumption ${ }^{9,22}$ that female-headed households are economically worse off than male-headed households, if only taking into account income figures.

\section{Influence of power relations on daily experiences of people (worries about food and experience of bunger)}

We investigated how the revealed power relations influence the daily experiences of people. The correlation between power relations and worries about food and experiences of hunger is indicated in Table 3.

It is striking that, in households where men dominate, there were more worries about the food situation than in households with partnership relationships and in households led by women. This is despite the fact that per capita incomes in men-led households were higher than in both of the other categories. In households with partnership relationships, the incidence of experiencing hunger on the part of both interviewees and their children was lower than in the other categories. In households with men dominating, the number of interviewees indicating that they go hungry was slightly lower than in women-led households, but $60 \%$ indicated that there is sometimes not enough food for children. This is much higher than in households with partnership relationships and also higher than in women-led households.

\section{Influence of power relations on state of food security}

Correlating the state of food security with power relations leads to the picture shown in Table 4.

It becomes very clear that households where the relationship is based on a partnership are the most foodsecure. This is despite the lower per capita incomes that exist in these households compared with men-led households. In the latter category, the percentage of very insecure and insecure households is the highest of all three categories, despite the even more striking difference regarding per capita income with respect to households led by women.

As these results indicate, there are underlying factors that determine the success of households, with 'success' referring to the achievement of better nutrition security than other households despite similar difficult socioeconomic circumstances.

\section{Why housebolds are successful in managing with adverse situations}

The investigation into why some households are more successful than others revealed that this question cannot be answered in a simple way. However, certain characteristics came to the fore. Households manage more successfully with limited resources if:

1. there are several income earners and therefore also several decision-makers;

2. women are managing resources, which often includes that they also have access to small credits at local shops;

3. the household has access to networks of relatives and neighbours; and

Table 1 Selected characteristics of the different categories of food security

\begin{tabular}{|c|c|c|c|c|}
\hline \multirow[b]{2}{*}{ Characteristic } & \multicolumn{4}{|c|}{ Category of food security* } \\
\hline & Very insecure & Insecure & Relatively secure & Secure \\
\hline$\%$ of households & 16 & 58 & 21 & 5 \\
\hline Mean per capita income (Rand) & 57 & 159 & 353 & 2268 \\
\hline Mean household size & 7.5 & 7 & 5.4 & 4.8 \\
\hline$\%$ of total expenditure spent on food & 58 & 46 & 39 & 27 \\
\hline$\%$ of households having savings & 4 & 17 & 43 & 100 \\
\hline$\%$ of households owning livestock & 12 & 17 & 6 & - \\
\hline$\%$ of households regularly using small credit & 19 & 42 & 20 & - \\
\hline$\%$ of households having loans & 8 & 14 & - & - \\
\hline$\%$ of households having diversity of food & 12 & 36 & 69 & 88 \\
\hline
\end{tabular}

${ }^{*}$ For a detailed description of the different categories of food security, see Lemke ${ }^{10}$. 
Table 2 Association between power relations and per capita income

\begin{tabular}{lc}
\hline Power relations ${ }^{*}(n=100)$ & $\begin{array}{c}\text { Per capita } \\
\text { income† (Rand) }\end{array}$ \\
\hline Partnership $(n=14)$ & 340 \\
Men-led $(n=36)$ & 466 \\
Women-led $(n=47)$ & 148 \\
\hline
\end{tabular}

*In-depth investigation into the issue of 'head of household' revealed the three categories of power relations.

†Only households where reliable data on income could be obtained are included here. However, data on income should always be regarded with a degree of caution.

Table 3 Power relations, worries about food and experiences of hunger

\begin{tabular}{lccc}
\hline $\begin{array}{l}\text { Power relations } \\
(n=166)\end{array}$ & $\begin{array}{c}\text { Worried } \\
\text { about food }(\%)\end{array}$ & $\begin{array}{c}\text { Going hungry } \\
\text { yourself } \\
(\%)\end{array}$ & $\begin{array}{c}\text { Children } \\
\text { going hungry } \\
(\%)\end{array}$ \\
\hline Partnership $(n=30)$ & 48 & 17 & 25 \\
Men-led $(n=65)$ & 81 & 40 & 60 \\
Women-led $(n=71)$ & 80 & 44 & 49 \\
Significance of & $P \leq 0.001$ & $P \leq 0.033$ & $P \leq 0.017$ \\
$\quad$ correlation & & & \\
\hline
\end{tabular}

Table 4 State of food security according to power relations (significance of correlation: $P \leq 0.001$ )

\begin{tabular}{lrccc}
\hline & \multicolumn{4}{c}{ State of food security (\%) } \\
\cline { 2 - 6 } $\begin{array}{l}\text { Power relations } \\
(n=166)\end{array}$ & Very insecure & Insecure & $\begin{array}{c}\text { Relatively } \\
\text { secure }\end{array}$ & Secure \\
\hline Partnership $(n=30)$ & 7 & 33 & 47 & 13 \\
Men-led $(n=65)$ & 19 & 66 & 12 & 3 \\
Women-led $(n=71)$ & 17 & 62 & 18 & 3 \\
\hline
\end{tabular}

4. the relationship between a couple is based on equal partnership.

In some cases one, in other cases several, of the above characteristics apply.

In contrast, households manage less successfully if:

1. they are male-dominated households;

2. intra-household relations reveal struggle and tension about household resources;

3. household members are totally dependent on others due to illness or having no income;

4. there is 'unwise' budgeting;

5. the household head is a pensioner or in a weak position according to his age; and

6. single mothers with children who lack social networks form a household.

Households led by women, despite more limited economic resources, are not as disadvantaged as one would expect. They often even achieve a status better than or equal to that of households led by men, with social networks of relatives and friends being of great importance.

\section{Case studies: bighlighting the findings and} illustrating real lives

The following case studies describe shared decisionmaking (Case 1) and unequal distribution of resources (Case 2), and illustrate the impact on the well-being of the households concerned. The case studies reflect phenomena commonly found in the study sample and therefore represent the experiences of other similar cases.

- Case 1: A married couple, 54 and 59 years old, with their four children, aged 17-26, and five grandchildren, aged 1-11. Per capita income is R91 per month. The interviewee is the husband, who is unemployed. He calls himself 'head', but indicates that his wife and daughter mainly make decisions. Therefore, this household was classified as de facto female-headed. The wife gets a pension and the daughter works. Other children sometimes contribute food. In case of food shortage, they can buy with credit at the local supermarket. Food diversity is very limited: vegetables, meat and fruit are very rare. Expenditure on food is about $60 \%$ of total expenditure. There is mutual co-operation between the household members: I have been staying here since being out of a job on the farms. I took my money and came here to build myself a bouse with my wife and children. I stay with my people because they belp me to take care of my bousebold... what worries me is that I'm unable to belp my children and myself with money, because I have no income whatsoever, because of unemployment and my illness.

This household was categorised as food-insecure. Regarding the fact that per capita income is considerably lower than the average per capita income in this category (R159, see Table 1), this household can be regarded as successful under the circumstances. Because of good support amongst one another and additional contributions in kind, this household is doing better than one would expect, as its members at least experience no hunger or food shortage. In a quantitative investigation, information on both the true head of household as well as the actual situation of this household, regardless of income, would probably have been missed.

- Case 2: A woman in ber fifties, living witb the 18-year-old daughter, ber 4-montb-old grandchild and a son in bis twenties. M states in the qualitative in-depth interview that she earns some money doing the washing for other people, while she states in the quantitative sociodemographic questionnaire that she does not have a job or an income of her own. When we ask what her son, who has contract work, contributes to household income, she becomes very angry and states that he does not give them enough money. To the question 'What could improve the situation regarding food?', the daughter says: 'We must buy more food, so 
that there is more food in the house - there is enough money, we can do it.' At a later visit we find that $\mathrm{M}$ is no longer able to work because she broke her arm. Another son has moved in and she now depends solely on money earned by her two sons. When we ask her again about contributions of her two sons, she indicates that she does not know what they earn, but assumes that it must be about R1000 per month each. Both herself and her daughter get just a little money from them to buy food, which only lasts to get them over a few days. Then M regularly seeks help from another daughter who lives in the same location and also seeks assistance from neighbours.

This example reveals tension and unequal distribution of resources within this household. It is difficult to determine who is head of household, as decision-making changes with the economic situation. As people do not regard informal work as a proper job, contradictory statements as given here might be found. As long as $\mathrm{M}$ was able to do washing, this additional income contributed considerably to household resources and enabled her to buy food or other commodities. At that stage, the household was classified as food-insecure. After M broke her arm, she and her daughter moved into the very food-insecure category. They have no access to household income that would enable them to achieve better food security. Also, in this case, the qualitative investigation uncovers both the economic situation and the social networks of this household.

\section{Conclusion and outlook}

The combination of poverty, unemployment, violence, social disruption, the disempowered status of many rural and peri-urban women and the high incidence of $\mathrm{HIV}$ infections in South $\mathrm{Africa}^{23}$ all gives reason for great concern. However, despite the breaking up of conjugal relationships and the resulting changes in household organisation, the reliance on and fostering of social ties and networks appear to be of central significance. With the support of these networks, women furthermore find ways to empower themselves and to take control of their lives. These social circumstances must be borne in mind when dealing with issues concerning households, social relationships and nutrition security. In future investigations of underlying factors linked to food and nutrition security, 'alternatively constructed households' and the resultant wide networks must be taken into account. Qualitative research provides insights into the organisation of these households and how they manage their resources. No matter how complicated household structures and human interactions might be, if they are not recognised sound knowledge about households and social systems cannot be obtained.

\section{Acknowledgements}

This paper was presented at the 19th Biennial Congress of the Nutrition Society, Potchefstroom University, South Africa, 5-9 November 2002. The findings are part of a PhD study completed in $2001^{10}$. S.L. thanks her supervisors, H.H.V., J.Z. and N.S.J.v.R., for their support, as well as the interviewees and field assistants, without whom the research would not have been possible. The study was funded by a grant of the Technical University of MunichWeihenstephan and by the University of Potchefstroom.

\section{References}

1 Parikh KS. World food system: resilient for the rich, stubborn for the starving. SNC News/United Nations, Administrative Committee on Coordination, Subcommittee on Nutrition 2000; 20: 17-20.

2 De Haen H. Preparing for the World Food Summit: five years later. In: Civil Society and the UN System: Debate in the Food Security Arena [special issue]. SNC News/United Nations, Administrative Committee on Coordination, Subcommittee on Nutrition 2001; 23: 4-5.

3 Adams AM, Cekan J, Sauerborn R. Towards a conceptual framework of household coping: reflections from rural West Africa. Africa 1998; 68(2): 262-83.

4 Maxwell S, Smith M. Household food security: a conceptual review. In: Maxwell S, Frankenberger TR, eds. Housebold Food Security: Concepts, Indicators, Measurements. A Technical Review. New York: United Nations Children's Emergency Fund (UNICEF), 1992; 1-72.

5 Kennedy E, Peters P. Household food security and child nutrition: the interaction of income and gender of household head. World Development 1992; 20(8): 1077-85.

6 Van der Waal CS. Rural children and residential instability in the Northern Province of South Africa. Social Dynamics 1996; 22(1): 31-54.

7 Spiegel AD, Watson V, Wilkinson P. Domestic diversity and fluidity among some African households in Greater Cape Town. Social Dynamics 1996; 22(1): 7-30.

8 Liebenberg A. Dealing with relationships of inequality. Married women in a Transkei village. In: McAllister PA, ed. Culture and the Commonplace. Johannesburg: Witwatersrand University, 1997; 349-73.

9 Jones S. Singlehood for security: towards a review of the relative economic status of women and children in womanled households. Society in Transition, Journal of the South African Sociology Association 1999; 30(1): 13-27.

10 Lemke S. Food and nutrition security in black South African bouseholds: creative ways of coping and survival. Dissertation, Center of Life Sciences, Technical University of Munich-Weihenstephan, Germany, 2001 (http://tumb1. biblio.tu-muenchen.de/publ/diss/ww/2001/lemke.pdf).

11 Vorster HH, Wissing MP, Venter CS, Kruger HS, Kruger A, Malan NT, et al. The Impact of urbanization on physical, physiological and mental health of Africans in the North West Province of South Africa: The THUSA Study. South African Journal of Science 2000; 96: 1-10.

12 Creswell JW. Research Design. Qualitative and Quantitative Approaches. Thousand Oaks, CA: Sage, 1994.

13 Denzin NK, Lincoln YS, eds. Handbook of Qualitative Research. Thousand Oaks, CA: Sage, 1994.

14 Miles MB, Hubermann AM. Qualitative Data Analysis. London: Sage, 1994.

15 Rubin HJ, Rubin IS. Qualitative Interviewing. The Art of Hearing Data. Thousand Oaks, CA: Sage, 1995. 
16 Koen E. Women's empowerment: a threat to the family? Welfare Focus 1994; 29: 13-8.

17 Niehaus IA. Disharmonious spouses and harmonious siblings: conceptualising household formation among urban residents in Qwaqwa. African Studies 1994; 53(1): $115-35$.

18 Van der Vliet V. Traditional husbands, modern wives? Constructing marriages in a South African township. In Spiegel AD, McAllister PA, eds. Tradition and Transition in Southern Africa. Johannesburg: Witwatersrand University Press, 1991; 219-41.

19 Food and Agriculture Organization (FAO). Rome Declaration on World Food Security and World Food Summit Plan of Action. Rome: FAO, 1996; 7.
20 Evans A. Statistics. In: Ostergaard L, ed. Gender and Development. London: Routledge, 1992; 11-40.

21 May J, Woolard I, Klasen S. The nature and measurement of poverty and inequality. In: May J, ed. Poverty and Inequality in South Africa: Meeting the Challenge. Cape Town: David Philip, 2000; 19-48.

22 Von Braun J. Food security - a conceptual basis. In: Kracht U, Schulz M, eds. Food Security and Nutrition. The Global Challenge. New York: St. Martin's, 1999; 41-53.

23 Joint United Nations Programme on HIV/AIDS (UNAIDS)/ World Health Organization (WHO). AIDS Epidemic Update. UNAIDS/WHO 2002, December 2002 (http:// www.unaids.org). 